\title{
Fabrication of PZT-polymer composite materials having 3-3 connectivity for hydrophone applications
}

\author{
N M GOKHALE, S C SHARMA and RAMJI LAL \\ Naval Chemical and Metallurgical Laboratory, Naval Dockyard, Bombay 400 023, India \\ MS received 19 March 1988; revised 24 June 1988

\begin{abstract}
Lanthanum-modified lead zirconate titanate (PZT) powder and volatilisable polymethylmethacrylate (PMM) polymer particles have been used for fabrication of porous sintered ceramics of interconnected porosity varying from $25 \%$ to $59 \%$. Sintered ceramics are converted into piezoelectric PZT-polymer composites by incorporating silicone rubber elastomer followed by electroding and poling. Influence of the variation of PZT-PMM ratio and sintering temperatures on the open and closed porosity of the sintered ceramics as well as volume fraction PZT in the composites has been studied and correlated for the optimization of piezoelectric properties. The PZT-polymer composites possess low density, considerably high piezoelectric voltage coefficient and considerably lower ageing characteristics and are therefore considered suitable for designing highly sensitive hydrophone systems.
\end{abstract}

Keywords. PZT-polymer; composite; connectivity patterns; piezoelectric voltage coefficient.

\section{Introduction}

Ceramics having piezoelectric properties are being increasingly used in electronic devices. Among such materials lead zirconate titanate (PZT) solid solutions are widely used because of their superior properties and versatility over other materials. Piezoelectric voltage coefficient $\left(g_{33}\right)$ is an important parameter of transducer materials for hydrophone applications. This parameter is related to piezoelectric strain coefficient $\left(d_{33}\right)$ and dielectric constant $(\varepsilon)$ as follows: $g_{33}=d_{33} / \varepsilon_{33}^{T}$. Thus a problem arises during the use of single phase PZT in hydrophone because of its higher $\varepsilon$ which results in a low piezoelectric voltage response to pressure change. Higher density of PZT does not allow efficient acoustic coupling with water in hydrophones. In addition, the $d_{33}$ value of PZT being approximately equal to $-2 d_{31}$ lowers its hydrostatic sensitivity. Considerable efforts have therefore been made towards reducing the value of $\rho, \varepsilon, d_{31}$ and $d_{32}$ of PZT by incorporating polymer as a low density and low permittivity phase in various connectivity patterns. Newnham et al $(1978,1980)$ used polymer as a second phase to laterally interconnect the ceramic phase. Safari's (1983) approach in this respect is based on the development of a structure embedded by elongated voids in solid PZT in a direction perpendicular to poling field. Another approach by Shrout et al (1979) based on the development of PZT-polymer composite having 3-3 connectivity has also shown encouraging results. Recently Khan et al (1986) and Haun et al (1986) have produced materials with hydrostatic sensitivity nearly four orders of magnitude greater than the conventional PZT. These indicate that the piezoelectric properties of the composites are dependent on total porosity, pore structure and connectivity patterns of various phases which are considerably influenced with the variation in composition and processing parameters. However, the data available in this respect are limited. The objective of the present investigation is, therefore, to 
study the influence of the variation of PZT/PMM ratio, open and closed porosity and sintering parameters on the piezoelectric properties of PZT-polymer composites having 3-3 connectivity.

\section{Experimental}

PZT powder of composition $\mathrm{Pb}_{0.955} \mathrm{La}_{0.030}\left(\mathrm{Zr}_{0.55} \mathrm{Ti}_{0.45}\right) \mathrm{O}_{3}$ and particle size in the range of $1-2 \mu \mathrm{m}$ was used in the present investigation. Volatilisable polymethylmethacrylate (PMM) particles varying between 50 and $150 \mu \mathrm{m}$ in diameter were used for pore formation. Four batches of powders namely A,B,C and D having PZT and PMM ratio 60:40,50:50, 40:60 and 30:70 respectively were prepared by thoroughly mixing in a homogenizer for $24 \mathrm{~h}$. The mixed powders were compacted into circular discs of $24 \mathrm{~mm}$ diameter at $140 \mathrm{MPa}$ using $6 \mathrm{wt} \%$ PVA as binder. Pores were formed by heating the compacted samples to $600^{\circ} \mathrm{C}$ at a slow heating rate of $40^{\circ} \mathrm{C} / \mathrm{h}$ upto $300^{\circ} \mathrm{C}, 60^{\circ} \mathrm{C} / \mathrm{h}$ from 300 to $450^{\circ} \mathrm{C}$ and thereafter $100^{\circ} \mathrm{C} / \mathrm{h}$ to prevent cracking during PMM removal. The porous samples were then sintered for $2 \mathrm{~h}$ in $\mathrm{SiC}$ resistance heating furnace at temperatures varying from $1100^{\circ} \mathrm{C}$ to $1300^{\circ} \mathrm{C}$ under $\mathrm{PbO}$ atmosphere. For sintering samples were assembled as shown in figure 1 to suppress the lead volatility. Homogeneity of the mixed powders was verified by studying or variation in the weight loss in the samples after PMM removal. Open and closed porosity of the sintered ceramics was determined by the Archimedes principle using xylene. Porous sintered ceramics were impregnated with silicone rubber elastomer (SILPOT-10 of $\mathrm{M} / \mathrm{s}$ Metroark Ltd.) by applying vacuum of $10^{-2} \mathrm{~mm}$ of $\mathrm{Hg}$ and cured for $24 \mathrm{~h}$. Samples of PZT-polymer composites thus obtained were lapped and polished using $\mathrm{SiC}$ paper and diamond paste to make their surfaces flat and parallel which were electroded by applying air drying silver paste (epo-tek $\mathrm{H} 2 \mathrm{OE}$ ). Electroded samples were poled by applying a d.c. electric field of $30 \mathrm{kV} / \mathrm{cm}$ at $100^{\circ} \mathrm{C}$ for 15 minutes in a silicone oil bath. The density of the composite was determined by dimensional measurements after lapping and their piezoelectric properties were measured $24 \mathrm{~h}$ after poling.

The dielectric constant $(\varepsilon)$ was measured at $1 \mathrm{kHz}$ using an automated capacitance bridge and the piezoelectric strain coefficient $\left(d_{33}\right)$ was determined by Berlincourt piezo $-d_{33}$-meter. The piezoelectric voltage coefficient $\left(g_{33}\right)$ was calculated using the formula.

$$
g_{33}=d_{33} / \varepsilon_{33}^{T} \text {. }
$$

Polished specimens were examined by scanning electron microscopy (SEM) and their photomicrographs were obtained.

\section{Results and discussion}

The per cent weight loss of the compacted samples after PMM removal and sintering at $1200^{\circ} \mathrm{C}$ is given in table 1 . The negligible variation in weight loss from sample to sample in a batch after PMM removal indicates homogeneous distribution of PMM particles in the mixed powders. There is no significant change in sample weight after sintering which indicates that volatility of $\mathrm{PbO}$ has been suppressed and the stoichiometry of the powder is maintained. Open porosity of the sintered ceramics increases with increase in PMM content of mixed powders 


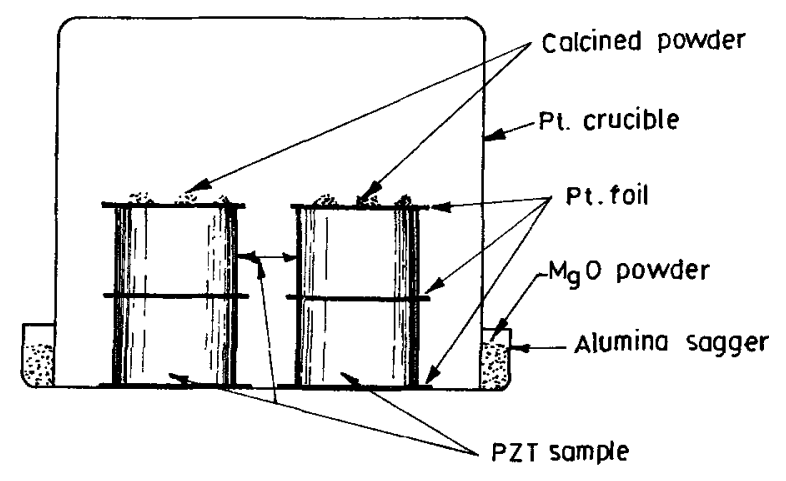

Figure 1. Schematic arrangement for sintering porous PZT ceramics.

Table 1. Density and porosity of porous ceramics sintered at $1200^{\circ} \mathrm{C}$ for $1 \mathrm{~h}$.

\begin{tabular}{ccccccc}
\hline $\begin{array}{c}\text { Batch desig- } \\
\text { nation }\end{array}$ & $\begin{array}{c}\text { PZT-PMM } \\
\text { ratio }\end{array}$ & $\begin{array}{c}\text { Wt. loss } \\
\text { during PMM } \\
\text { removal (\%) }\end{array}$ & $\begin{array}{c}\text { Wt. loss } \\
\text { during sinter- } \\
\text { ing }(\%)\end{array}$ & $\begin{array}{c}\text { Density of } \\
\text { porous PZT } \\
(\mathrm{g} / \mathrm{cc})\end{array}$ & $\begin{array}{c}\text { Open poro- Closed poro- } \\
\text { sity (\%) }\end{array}$ & $\begin{array}{c}\text { sity }(\%) \\
\text { sing }\end{array}$ \\
\hline A & $60: 40$ & $10 \cdot 12$ & 0.09 & $3 \cdot 64$ & $48 \cdot 5$ & $4 \cdot 2$ \\
B & $50: 50$ & 14.16 & 0.07 & 3.49 & $52 \cdot 2$ & $2 \cdot 5$ \\
C & $40: 60$ & 19.73 & 0.08 & 3.23 & $55 \cdot 6$ & $2 \cdot 5$ \\
D & $30: 70$ & 27.67 & 0.10 & 2.93 & $59 \cdot 0$ & $2 \cdot 9$ \\
\hline
\end{tabular}

whereas no significant trend has been observed in the closed porosity. Open porosity of the sintered ceramics decreases and closed porosity increases with the rise in sintering temperature as shown in figure 2. Decrease in the values of open porosity can be explained due to the pore closure whereas increase in closed porosity is attributed to the entrapment of pores with the rise in sintering temperature. The curves plotted in figure 2 can also be extrapolated to determine the values of open and closed porosity for other intermediate compositions and sintering temperature with accuracy.

Variation of dielectric and piezoelectric properties of the composites with volume fraction PZT is shown in figure 3. The values of $\varepsilon$ and $d_{33}$ decrease with decrease in the volume fraction PZT in the composites thereby confirming the relationship proposed by Rittenmyer et al (1982). Variation of $g_{33}$ with volume fraction PZT exhibits a very interesting trend. The values of $g_{33}$ increase initially with increase in volume fraction PZT but decrease considerably when the volume fraction PZT exceeds 0.42 in the composites. Decrease in $g_{33}$ values at high volume fraction PZT can be attributed to the sharp increase in $\varepsilon$ values of composite at higher volume fraction PZT. The low values of $g_{33}$ at lower volume fraction PZT is due to the faster decrease in $d_{33}$ values compared to $\varepsilon$ values and the lower degree of interconnectivity in PZT phase. Thus there is an optimum ratio of PZT and polymeric phase to obtain a maximum value of $g_{33}$ in the composite. It has been concluded on the basis of microstructure property correlation that sintered porous PZT with $50 \%$ open porosity and minimum closed porosity give maximum degree of interconnectivity between PZT and polymer phases and optimum piezoelectric properties. SEM photomicrograph of the composites having 0.42 volume fraction PZT is 


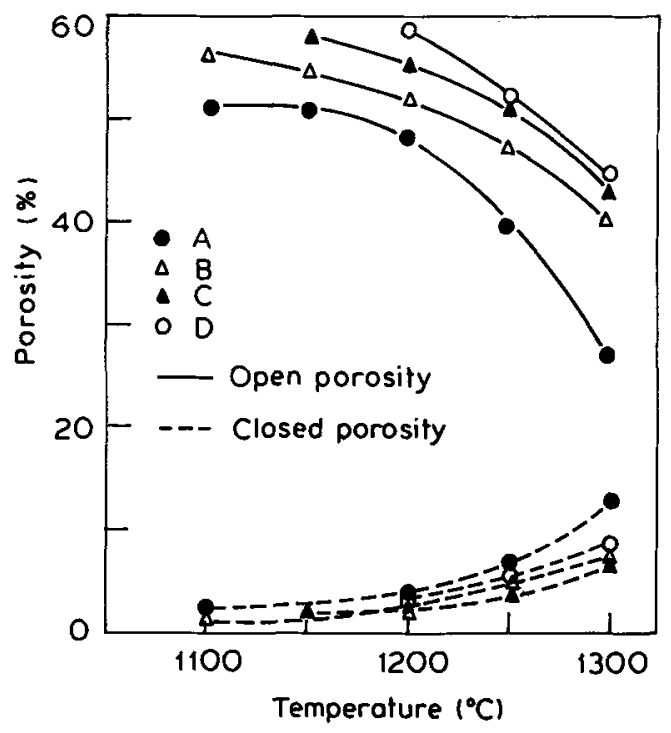

Figure 2. Variation of open and closed porosity with temperature of sintered porous ceramics.

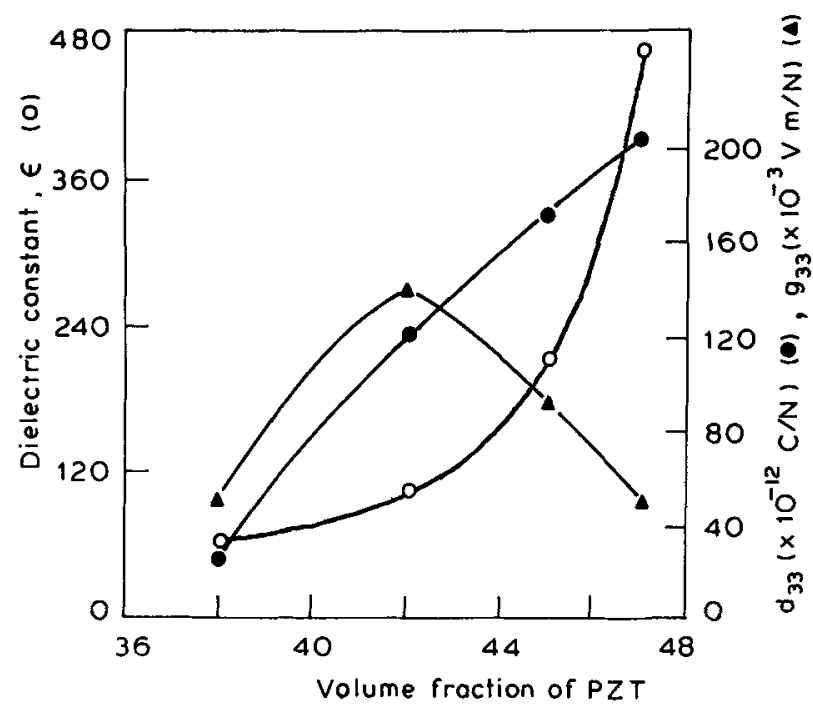

Figure 3. Variation of piezoelectric properties with volume fraction PZT in composite material.

shown in figure 4 which exhibits interconnectivity between PZT and polymeric phases and the size of the polymeric phase varies between $20 \mu \mathrm{m}$ and $120 \mu \mathrm{m}$. It is also apparent that the vacuum impregnation of polymer is nearly complete. The higher breakdown voltage of the composite $(>30 \mathrm{kV} / \mathrm{cm})$ also indicates that there is not much noticeable voids. Physical, dielectric and piezoelectric properties of 12 samples of a particular batch of PZT-polymer composite having volume fraction PZT between 0.42 and 0.44 are reported in table 2 . Since there is no significant 


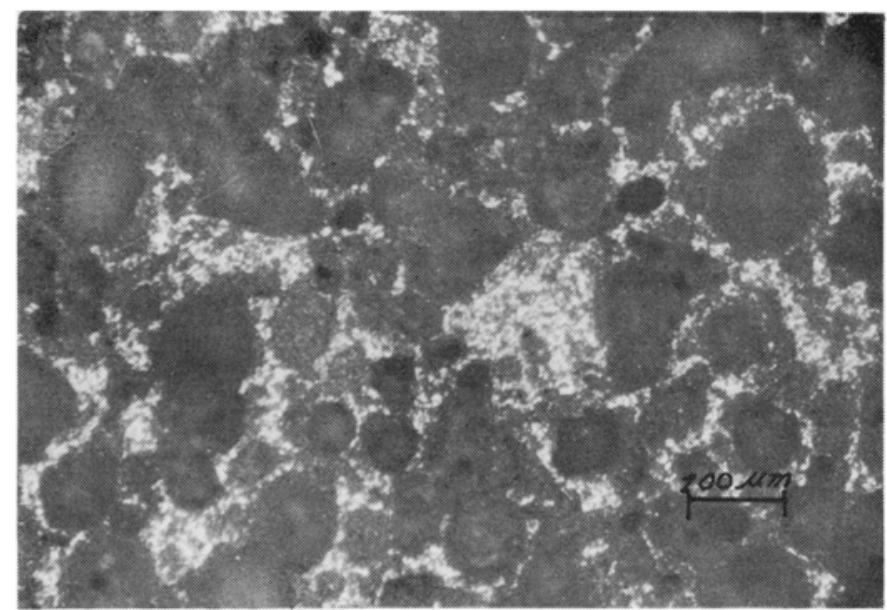

Figure 4. SEM photomicrograph of PZT-polymer composite.

Table 2. Piezoelectric properties of PZT-polymer composite material.

\begin{tabular}{lccccc}
\hline Sample no. & $\begin{array}{c}\text { Volume } \\
\text { fraction } \\
\mathrm{PZT}\end{array}$ & $\begin{array}{c}\text { Density } \\
(\mathrm{g} / \mathrm{cc})\end{array}$ & $\varepsilon$ & $\begin{array}{c}d_{33} \mathrm{C} / \mathrm{N} \\
\left(\times 10^{-12}\right)\end{array}$ & $\begin{array}{c}g_{33} \mathrm{VM} / \mathrm{N} \\
\left(\times 10^{-3}\right)\end{array}$ \\
\hline 1 & 0.42 & 3.74 & 121 & 152 & 142 \\
2 & 0.42 & 3.71 & 117 & 143 & 138 \\
3 & 0.42 & 3.72 & 124 & 156 & 142 \\
4 & 0.43 & 3.76 & 129 & 149 & 130 \\
5 & 0.43 & 3.74 & 118 & 142 & 136 \\
6 & 0.42 & 3.68 & 110 & 128 & 131 \\
7 & 0.42 & 3.70 & 120 & 148 & 139 \\
8 & 0.42 & 3.72 & 116 & 157 & 153 \\
9 & 0.43 & 3.73 & 113 & 144 & 144 \\
10 & 0.43 & 3.75 & 120 & 147 & 138 \\
11 & 0.44 & 3.73 & 132 & 158 & 135 \\
12 & 0.42 & 3.70 & 123 & 153 & 140 \\
\hline
\end{tabular}

variation in the properties from sample to sample, the process is considered reproducible.

Ageing characteristics of PZT-polymer composite material shown in figure 5 indicate that the values of dielectric constant and $d_{33}$ constant decrease exponentially with ageing time at a very low rate. The slow ageing characteristics can be attributed to the presence of compliant polymer phase surrounding each PZT grain in the material. However, the $g_{33}$ values remain almost unchanged with time as it is the ratio of $d_{33}$ and the dielectric constant.

\section{Conclusions}

Piezoelectric voltage coefficient $\left(g_{33}\right)$ of the PZT-polymer composites can be improved by optimising the PZT/PMM ratio in the mixed powder and sintering 


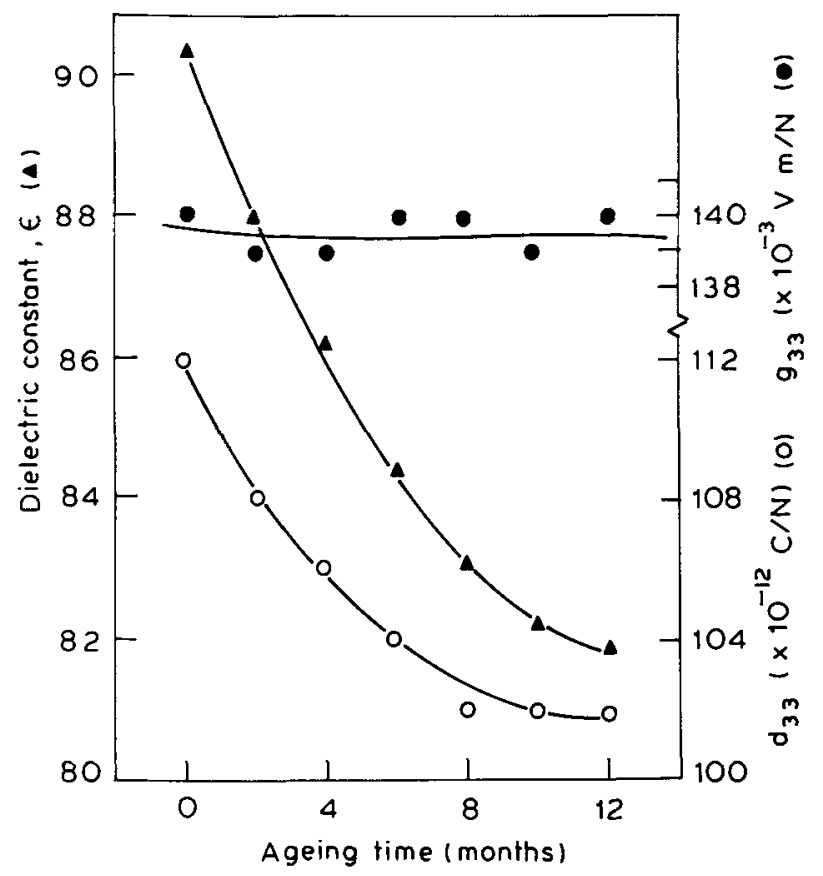

Figure 5. Ageing characteristics of PZT polymer composite materials.

parameters. Composites having 0.42 volume fraction PZT have shown a maximum value of $g_{33}$ in the entire compositional range. Using a homogeneous mixture of PZT and PMM powders and optimizing the sintering temperatures, it is possible to develop PZT-polymer composite in a reproducible manner having 3-3 connectivity and $g_{33}$ values in the range 130-150. The materials developed possess considerably low ageing characteristics in respect of piezoelectric voltage coefficient. Thus the process is considered industrially feasible for production.

\section{Acknowledgement}

The authors are grateful to Dr R Krishnan for his encouragement and interest.

\section{References}

Haun M J, Newnham R E and Schulze W A 1986 Adv. Ceram. Mater. 1361

Khan M, Rice R W and Shadwell D 1986 Adv. Ceram. Mater. 155

Newnham R E, Skinner D P and Cross L E 1978 Mater. Res. Bull. 13525

Newnham R E, Bowen L O, Klicker K A and Cross L E 1980 Mater. Eng. 293

Rittenmyer K, Shrout T, Schulze W A and Newnham R E 1982 Ferroelectrics 41181

Safari A 1983 Perforated PZT polymer composites with 3-1 and 3-2 connectivity for hydrophone applications, Ph.D. Thesis, The Pennsylvania State University

Shrout T R, Schulze W A and Biggers J V 1979 Mater. Res. Bull. 141553 